This is an informal report intended primarily for internal or

UCID - 16594 limited external distribution. (The opinions and conclusions stated are those of the author and may or may not be those of the laboratory.) This report is not to be given additional external distribution or cited in external documents without the consent of the author or LLL Technical Information Department.

\author{
近 \\ LAWRENCE LIVERMORE LABORATORY \\ University of California/Livermore, California
}

\title{
ELECTROMAGNETICALLY INDUCED PLASMA BACK CURRENT NEAR THE HEAD OF A RELATIVISTIC ELECTRON BEAM ENTERING GAS*
}

R. J. Briggs

E. J. Lauer and E. P. Lee

September 20, 1974

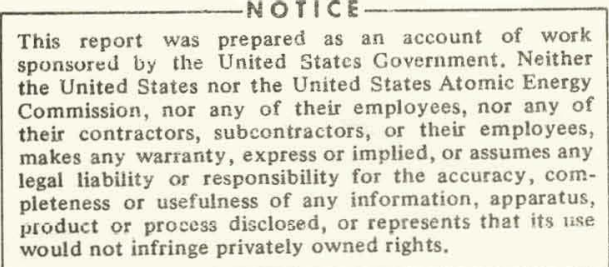

would not infringe privately owned rights.

*Work performed jointly under the auspices of the U.S. Atomic Energy Commission, and the Department of the Navy under the contract number NAonr 13-74.

Prepared for U. S. Atomic Encrgy Commission under contract no. W 7405 Eng 48 


\section{DISCLAIMER}

This report was prepared as an account of work sponsored by an agency of the United States Government. Neither the United States Government nor any agency Thereof, nor any of their employees, makes any warranty, express or implied, or assumes any legal liability or responsibility for the accuracy, completeness, or usefulness of any information, apparatus, product, or process disclosed, or represents that its use would not infringe privately owned rights. Reference herein to any specific commercial product, process, or service by trade name, trademark, manufacturer, or otherwise does not necessarily constitute or imply its endorsement, recommendation, or favoring by the United States Government or any agency thereof. The views and opinions of authors expressed herein do not necessarily state or reflect those of the United States Government or any agency thereof. 


\section{DISCLAIMER}

Portions of this document may be illegible in electronic image products. Images are produced from the best available original document. 


\title{
ELECTROMAGNETICALLY INDUCED PLASMA BACK CURRENT \\ NEAR THE HEAD OF A RELATIVISTIC \\ ELECTRON BENM ENTERING G/S*
}

\author{
R. J. Briggs, E. J. Lauer and E. P. Lee \\ July, 1974
}

\section{Introduction}

The dynamics of a self-focused relativistic beam entering unionized gas are strongly dependent on the initial rate of generation of conductivity. This conductivity generation is important in determining the stability of the beam to transverse (hose) modes, and it also enters into the self-focusing of the beam by its influence on the generation of back plasma currents.

The purpose of the present report is to present a simple. thcoretical description of the influence of the conductivity generation near the beam head on the plasma back current. Diagnostic techniques for measuring the beam and plasma currents at different axial locations have been developed, and the present theoretical treatment can help in the interpretation of this data, including the deduction of conductivity from the back current measurements. 
Analysis

We use an idealized model with cylindrical coordinates

$(r, \theta, z)$ and dependence only upon the radial coordinate $r$ and the time, $t$. $t$ is the local time after the head of the primary beam has passed the fixed observation point at axial position $z$. We assume that the primary beam has a total current $I_{b}(t)$ and uniform current density inside $r=r_{b}$ (see Fig. 1). The plasma conductivity $\sigma(t)$ is uniform inside $r=r_{c}=r_{b}$. There is a perfectly conducting wall at $r=r_{w}$. Between $r=r_{C}$ and $r=r_{W}$ the plasma conductivity is low enough so that the plasma current density is negligible. The conductivity is high enough in a.1. regions so that electrostatic fields are negligible, i.e. $(4 \pi \sigma)^{-1}$ is smaller than any time period of interest. Also the displacement current ( $\partial E / \partial t$ ) makes a negligible contribution to the magnetic field.

The z-component of time dependent plasma current is

$$
I_{p}=\pi r_{c}^{2} \sigma E
$$

where $E$ is the $z$-component of time dependent electric field. $E$ is given by

$$
E=-\frac{1}{C} \quad \frac{\partial \Phi}{\partial \tau}
$$

where $\Phi$ is the $\theta$-component of magnetic flux per on of $z$ between $r=r_{c}$ and $r=r_{W}$ (We neglect the flux inside $r=r_{c}$, and so $E$ and the plasma current density are uniform inside $r=r_{c}$ ). $\Phi$ is found 
by integrating $B_{\theta}(r) d r$ between $r=r_{c}$ and $r=r_{w}$;

$$
\Phi=\frac{2}{\mathrm{c}} \ln \frac{\mathrm{r}_{\mathrm{w}}}{\mathrm{r}_{\mathrm{c}}}\left(\mathrm{I}_{\mathrm{b}}+\mathrm{I}_{\mathrm{p}}\right)
$$

We assume that the plasma conductivity is given by

$$
\sigma=\frac{e^{2} n_{e}}{m v_{m}}
$$

where $n_{e}$ is the time dependent plasma electron density and $\nu_{m}$ is the momentum transfer collision frequency with gas molecules. (We assume that the fractional contribution to the collision frequency of the reactive term $\left(\omega / \nu_{m}\right)$ is negligible. Also, the gas molecule density is much larger than $n_{e}$ so collisions with plasma ions are neglected and $\nu_{m}$ is constant for a particular gas molecule density. Combining Eqs. 1-3 gives

$$
I_{p}=-\tau_{m}\left(\frac{\partial I_{b}}{\partial t}+\frac{\partial I_{p}}{\partial t}\right)
$$

where $\tau_{m}$ is the time constant for resistive decay of monopole plasma current distribution

$$
\tau_{m}=\frac{2 \pi \sigma r_{c}^{2}}{c^{2}} \ln \frac{r_{w}}{r_{c}}
$$

First Case: Time rate of increase of $\mathrm{n}_{\mathrm{e}}$ proportional to instantaneous beam current.

At relatively high gas pressures, the generation of plasma 
would be expected to be dominated by classical single-particle processes of ionization by the relativistic particles, hence we expect $\partial \mathrm{n}_{\mathrm{e}} / \partial \mathrm{t} i \mathrm{~J}_{\mathrm{b}}$ in the initial phases before recombination plays a role. Neglecting the dependence of $\nu_{\mathrm{m}}$ on electron temperature we have $\tau_{\mathrm{III}} \sim \mathrm{na}^{2} \sim \mathrm{n}_{\mathrm{e}} \mathrm{a}^{2}$, and therefnre

$$
\frac{\partial \tau_{m}}{\partial t}=\frac{I_{b}(t)}{I_{b 1}}
$$

The constant $\mathrm{I}_{\mathrm{bl}}$ can be calculated for a given gas; it has the physical significance of being the beam current for which $\left(\partial \tau_{m} / \partial t\right)=1$. This form of normalization is used because $\tau_{m}$ is the same as the dipole time constant $\left(\tau_{d}\right)$, except for a geometrical factor, and $\left(\partial \tau_{d} / \partial t\right) \stackrel{\sim}{1}$ is considered to be a condition for avoiding excessive growth of resistive hose instability near the beam bead.

We assume that the primary beam current increases linearly with time

$$
I_{b}(t)=I_{b 1} \frac{t}{\tau_{b}},
$$

so $\left(I_{b 1} / \tau_{b}\right)$ is the rate of increase.

Combining Eqs. 7 and 8, we have

$$
\frac{\partial \tau}{\partial \tau}=\frac{t}{\tau_{b}}
$$


Integrating Eq. 9 yields

$$
\tau_{m}=\frac{1}{\tau_{b}} \int_{t^{\prime}=0}^{t} t^{\prime} d t^{\prime}=\frac{t^{2}}{2 \tau_{b}} .
$$

Combining Fqs. 5, (d/dt) of 8 , and $\mathrm{Eq}$. 10 we have

$$
I_{p}=-\frac{t^{2}}{2 \tau_{b}}\left(\frac{I_{b 1}}{\tau_{b}}+\frac{d I}{d t}\right), 0 \leq t<\infty \text {. }
$$

To eliminate dimensions in Eq. (11) we define

$$
\begin{aligned}
& \frac{I_{p}}{I_{b 1}}=I, \\
& \frac{t}{\tau_{b}}=\frac{2}{x}
\end{aligned}
$$

Then Eq. (11) becomes

$$
\frac{d I}{d x}=I+\frac{2}{x^{2}}, \infty \geq x>0
$$

Eq. (14) is readily solved using an integrating factor:

$$
e^{x} \frac{d}{d x} \quad I e^{-x}=\frac{d I}{d x}-I=\frac{2}{x^{2}}
$$

This yields

$$
I e^{-x}=-\int_{x^{\prime}=x}^{\infty} d x \cdot \frac{2}{x^{-2}} e^{-x^{\prime}}+c
$$


Integrating once by parts we have

$$
I e^{-x}=-\frac{2}{x} e^{-x}+\int_{x}^{\infty} d x-\frac{2 e^{-x^{\prime}}}{x^{\prime}}+c
$$

or

$$
I=-\frac{2}{x}+2 e^{x} \varepsilon(x)+C e^{x},
$$

where

$$
\varepsilon(x)=\int_{x}^{\infty} \frac{d x^{-}}{x^{-\prime}} e^{-x^{\prime}}
$$

is a form of the "Exponential Integral", a tabulated function.

Our initial condition is that at $t=0(x=\infty), I=0$, so $C=0$. If we divide both sides of $\mathrm{Eq} .(18)$ by $(-2 / x)$ we have the magnitude of the plasma current at any time divided-by the beam current at that time.

$$
-\left(\frac{I_{p}(t)}{I_{b 1 \frac{t}{\tau_{b}}}}\right)=1-x e^{x} \varepsilon(x)
$$

For large $x$ an asymptotic expansion of Eq. (19) is found by successive integrations by parts: 


$$
\begin{array}{r}
-\frac{I_{p}(t)}{I_{b 1 \frac{t}{\tau_{b}}}} \rightarrow 1-x e^{x}\left[\left.\frac{e^{-x^{-}}}{-x}\right|_{x} ^{\infty}-\left.\frac{e^{-x^{-}}}{-x^{-2}}\right|_{x} ^{\infty}+\left.2 \frac{e^{-x^{-}}}{-x^{-3}}\right|_{x} ^{\infty} \cdot \ldots\right] \\
=\frac{1}{x}-\frac{2 !}{x^{2}}+\frac{3 !}{x^{3}} \cdot \ldots \cdot \dot{z} \frac{1}{x}=\frac{1}{2} \frac{t}{\tau_{b}} .
\end{array}
$$

And as $t \rightarrow \infty$,

$$
-\left(\frac{I_{p}(t)}{I_{b 1} \frac{t}{\tau_{b}}}\right)+1
$$

Figure 2 presents a plot of $I_{p}(t) / I_{B}$ making use of Eq. (13) and the table of the Exponential Integral in Handbook of Mathematical Functions issued in 1964 by National Bureau of Standards.

Second Case: Time rate of increase of $n_{e}$ proportional to square of the beam current.

$$
\text { In order to find the effect of a change in the assumed rate }
$$
of increase of $n_{e}$ with time, we now analyze the same situation as above except that we replace Eq. (7) with

$$
\frac{\partial \tau_{m}}{\partial t}=\left(\frac{I_{b}(t)}{I_{b 1}}\right)^{2}
$$

This might model, for example, a case where breakdown of the gas by 
inductive E-field is increasing the rate of ionization over the classical rate. We still assume that the primary beam current increases linearly with time as

$$
I_{b}(t)=I_{b 1} \frac{t}{\tau_{b}}
$$

Combining Eqs. (20) and (21) gives

$$
\frac{\partial \tau_{m}}{\partial t}=\frac{t^{2}}{\tau_{b}^{2}} .
$$

Integrating Eq. (22)

$$
\tau_{m}=\frac{1}{3} \frac{t^{3}}{\tau_{b}^{2}}
$$

Combining Eqs. (5), (d/dt) of 8 and Eq. (23) we have

$$
I_{p}=-\frac{t^{3}}{3 \tau_{b}^{2}} \quad\left(\frac{I_{b 1}}{\tau_{b}}+\frac{d I_{p}}{d t}\right), 0 \leq t<\infty .
$$

With the definitions

$$
\begin{aligned}
& \frac{I_{p}}{I_{b 1}}=1, \\
& \frac{t}{\tau_{b}}=\frac{3}{x},
\end{aligned}
$$

eq. (24) becomes 


$$
\frac{d I}{d x}=\frac{x I}{3}+\frac{3}{x^{2}}, \infty \geq x>0
$$

The solution of Eq. (27) is found (using an integrating factor) to be

$$
\begin{aligned}
I= & -e^{x^{2} / 6} \int_{x}^{\infty} d x^{-\frac{3}{x^{2}}} e^{-x^{-2 / 6}}+C e^{x^{2 / 6}}= \\
& -\frac{3}{x}+e^{x^{2} / 6} \cdot \int_{x}^{\infty} d x^{-} e^{-x^{-2 / 6}}+C e^{x^{2} / 6}
\end{aligned}
$$

We may write this in the form

$$
I=-\frac{3}{x}+e^{x^{2} / 6} \sqrt{\frac{3 \pi}{2}} \operatorname{erfc}\left(\frac{x}{\sqrt{6}}\right)+c e^{x^{2} / 6},
$$

where

$$
\operatorname{erfc}(y)=\frac{2}{\sqrt{\pi}} \int_{y}^{\infty} d x^{-} e^{-x^{-2}}
$$

is the complementary error function.

$$
\begin{aligned}
& \text { Since } I_{p}(t=0)=0 \text { we must set } C=0 \text {, which leaves } \\
& \qquad I(x)=-\frac{3}{x}+e^{x^{2} / 6} \sqrt{\frac{3 \pi}{2}} \operatorname{erfc}\left(\frac{x}{\sqrt{6}}\right) .
\end{aligned}
$$

The ratio of the magnitude of plasma to beam current is

$$
-\frac{I_{p}}{I_{B}}=-\frac{I}{t / \tau_{b}}=-\frac{x I}{3}=1-\frac{x}{3} e^{x^{2} / 6} \sqrt{\frac{3 \pi}{2}} \operatorname{erfc}\left(\frac{x}{\sqrt{6}}\right) .
$$


As $t \rightarrow \infty(x \rightarrow 0)$

$$
-\frac{I_{p}}{I_{B}} \rightarrow 1-\sqrt{\frac{3 \pi}{2}} \frac{x}{3}=1-\sqrt{\frac{3 \pi}{2}} \frac{{ }^{\tau} B}{t}
$$

and as $x \rightarrow \infty$.

$$
I \rightarrow-\frac{9}{x^{3}}
$$

or

$$
-\frac{I_{p}}{I_{B}}=-\frac{I}{t / \tau_{b}}=-\frac{I}{3 / x} \rightarrow \frac{3}{x^{2}}=\frac{1}{3}\left(\frac{t}{\tau_{b}}\right)^{2} .
$$

On Fig. $3\left(-I_{p} / I_{b}\right)$ is plotted vs $\left(t / \tau_{b}\right)$. 
Discussion and Summary: The ratio of back plasma current to beam current is sketched as a function of time $\left(t / \tau_{b}\right)$ in Figs. 2 and 3 for the two different models of conductivity generation, assuming a linearly rising beam current. An alternate interpretation of these graphs is that they give the percentage return current at the end of the beam risetime, when the current has reached a final value $I_{f}$. The horizontal axis is then simply $\mathrm{I}_{\mathrm{f}} / \mathrm{I}_{\mathrm{bl}}$, where $\mathrm{I}_{\mathrm{bl}}$ has the interpretation of the beam current magnitude for which $\left(\partial \tau_{m} / \partial t\right)=1$.

An interesting aspect of these results is the fact that the percentage return current at $t=\tau_{r}$, when $I_{b}$ has risen to $I_{f}$, is independent of the actual risetime $\left(\tau_{r} \equiv \frac{I_{f}}{I_{b 1}} \tau_{b}\right)$. The physical explanation for this result is that the conductivity $\left(\tau_{m}\right)$ at $t=\tau_{r}$ becomes smaller as the risetime $\left(\tau_{r}\right)$ is reduced, but the inductive electric field becomes greater (since $a I / \partial t$ increases) thus resulting in the same plasma current at $t=\tau_{r}$, when $I_{b}=I_{f}$, for all values of $\tau_{r}$.

The results in Figures 2 and 3 show that significant plasma return currents $(20-30 \%)$ should occur if the peak current rises to a value comparable to $I_{b 1}$, thus approaching the regime $\partial \tau_{m} / \partial t \sim 1$. If the regimc $\partial \tau_{\mathrm{m}} / \partial t>1$ is achieved, a high degree of current neutralization $\left(I_{p} \sim-I_{B}\right)$ will be obtained.

We have only discussed the plasma currents generated during the beam risetime phase thus far. If a beam current waveform 
like that in Fig. 4 is assumed, and the first model for conductivity generation is used, the solution for $I_{p}$ with $t \geq{ }_{r}$ is

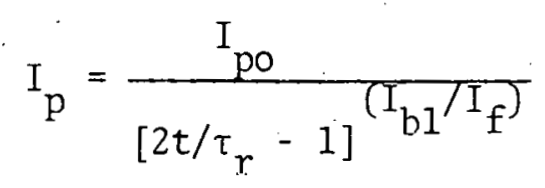

with $I_{\text {po }}$ the plasma current at $t=\tau_{r}$, as calculated above. The plasma current decays on a timescale governed by ${ }^{\tau_{r}}$ with an exponent determined by $\mathrm{I}_{\mathrm{f}} / \mathrm{I}_{\mathrm{bl}}$; smaller final currents decay faster, as expected, since the conductivity generation is weaker. Note that although $I_{p o}$ is independent of $\tau_{r}$, as discussed above, the plasma current decays on a timescale set by $\tau_{r}$; this is reasonable since $\tau_{m}\left(\tau=\tau_{r}\right) \rightarrow 0$ as $\tau_{r} \rightarrow \because$ The limit of a step-function $I_{b}(t)$, where $\tau_{r} \rightarrow 0$, would thus have $I_{N e t} \equiv I_{b}$ and the plasma current of finite amplitude and zero duration. As expected, an infinitely fast risctime beam injected into a nonconducting gas would not induce any measurable plasma return current at the head. 


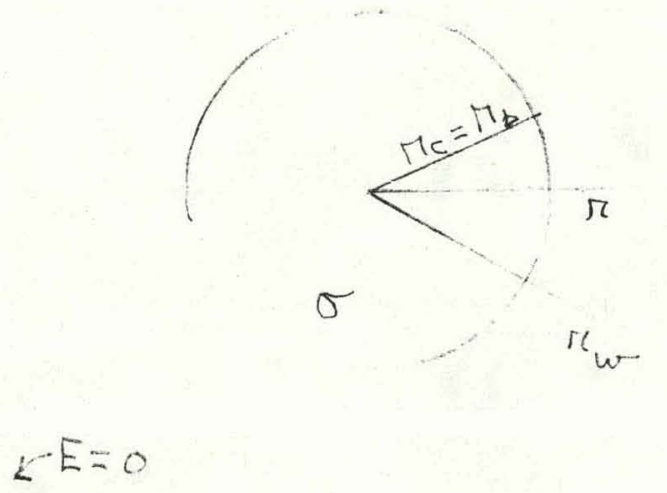

Fig. 1 Geometry for the idealized model. 


\section{- $I_{p} / I_{b}$}

$1 \frac{\uparrow}{1}$

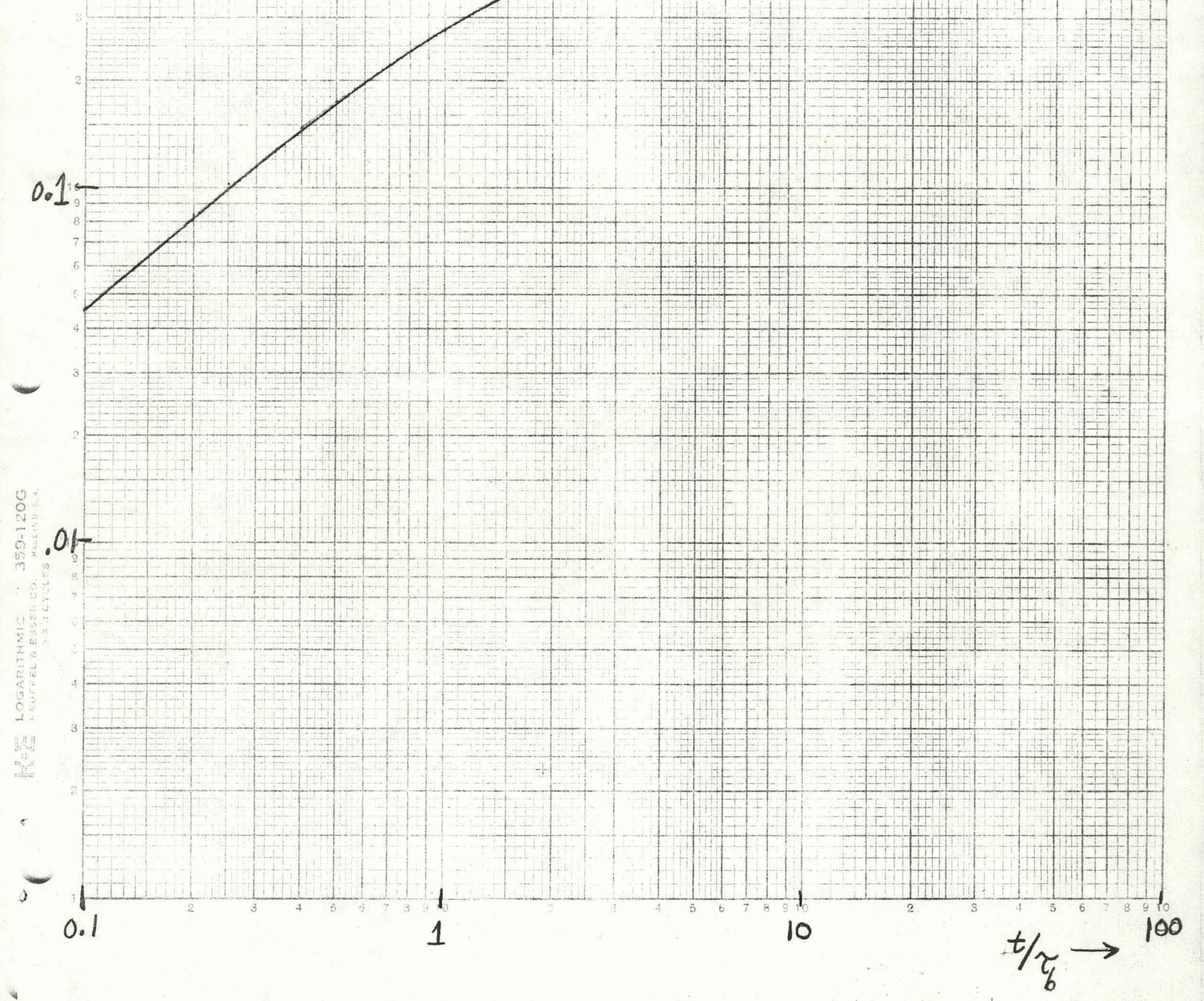

Fig $2\left[-I_{p}(t) / I_{b}(t)\right]$ vs $t / \tau_{b}=\partial \tau_{m} / \partial t=I_{b} / I_{b_{1}}$. 


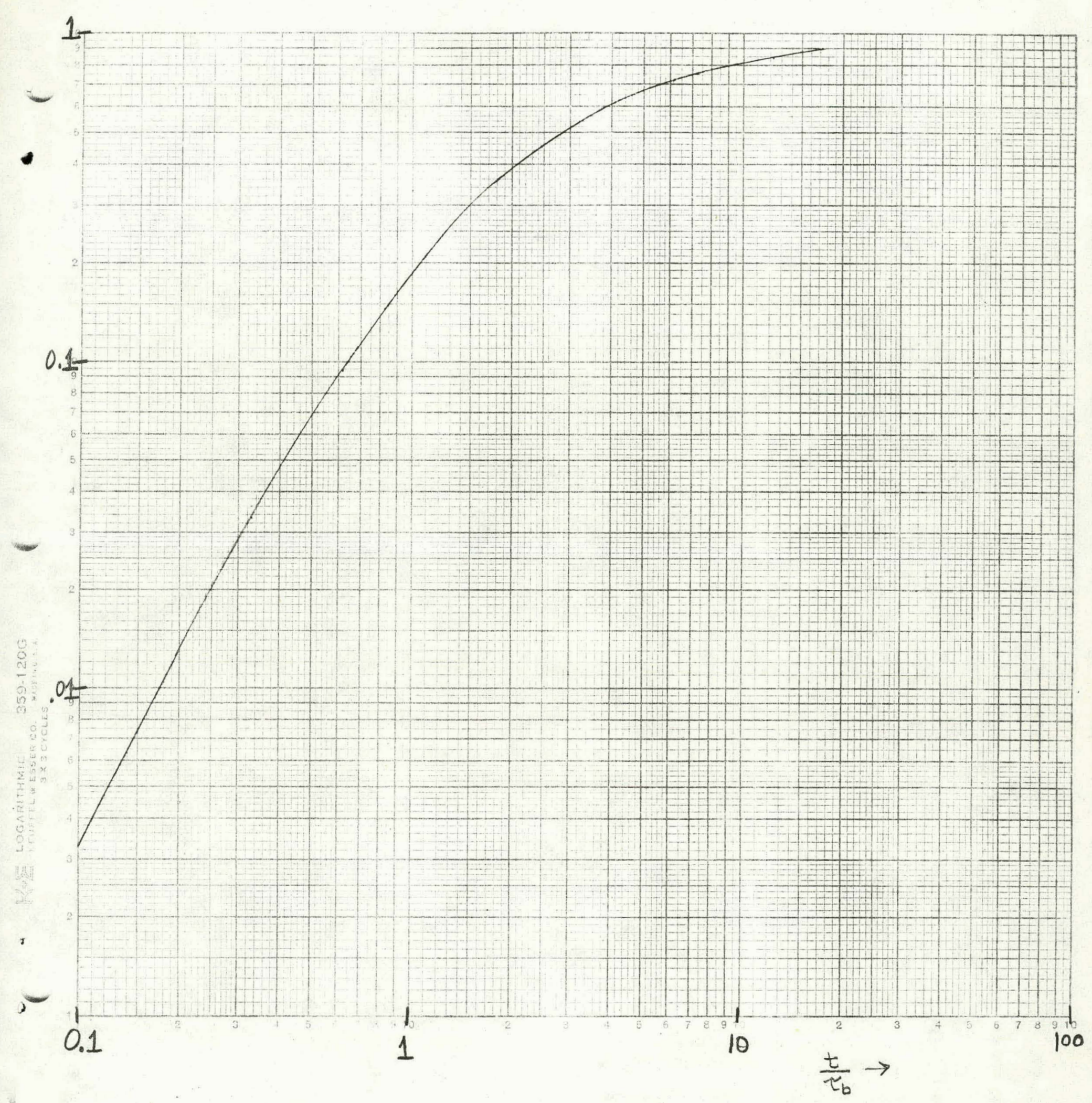

Fig. $3\left(-I_{p} / I_{b}\right)$ vs $\left(t / \tau_{b}\right)$ for $\left(\partial \tau_{m} / \partial t\right)=\left(I_{b} / I_{b_{1}}\right)^{2}$ and $\left(I_{b} / I_{b l}\right)=\left(t / \tau_{b}\right)$ 


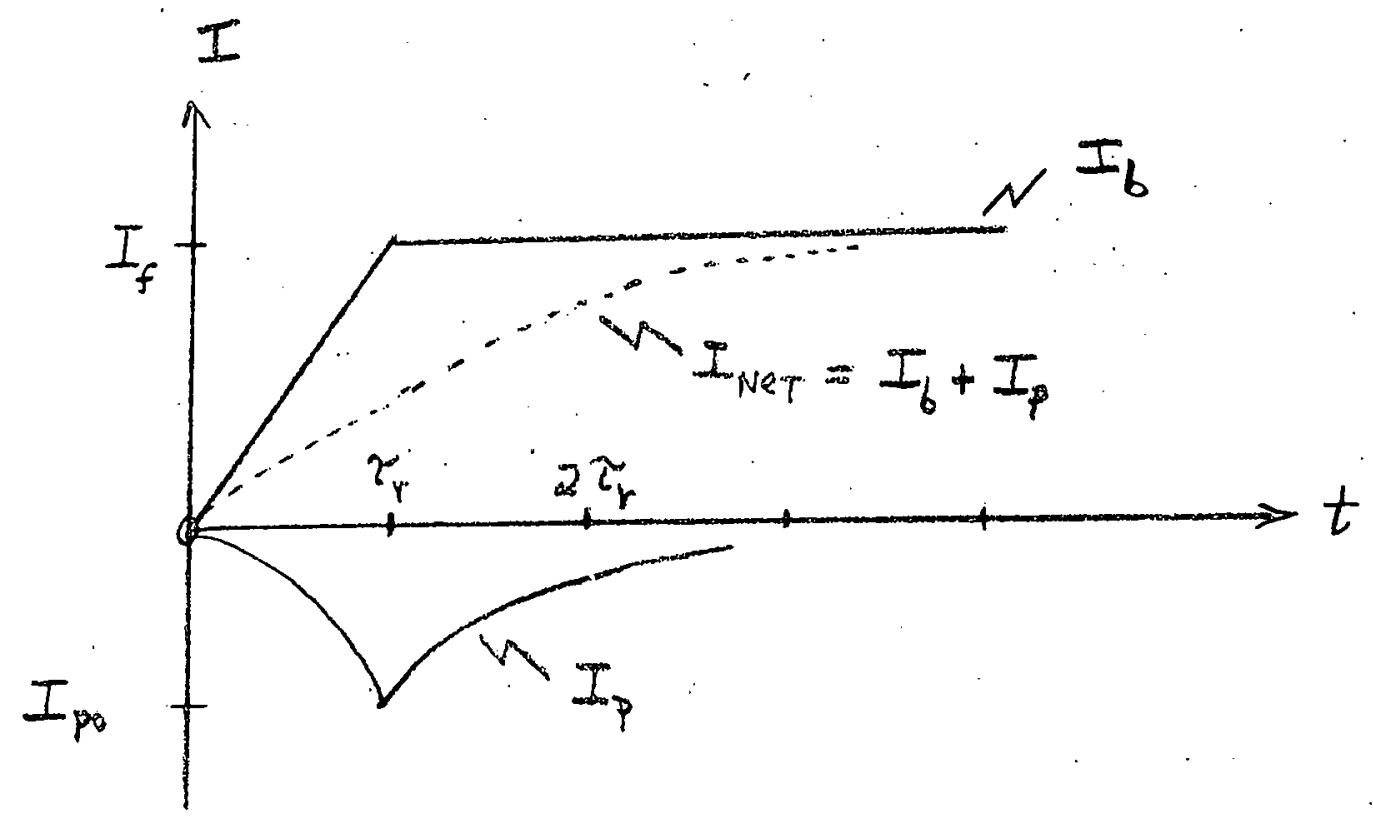

Fig 4. Qualitative nature of plasma current and net current with triangular beam shape and $\partial \tau_{m} / \partial \tau=I_{b} / I_{b l}$. 


\section{Distribution}

\section{Internal - LLL}

$\begin{array}{lll}\text { R. E. Batzel } & L-1 \\ \text { R. J. Briggs } & L-382 \\ \text { R. } & \text { Buntzen } & L-212 \\ \text { T. J. Fessenden } & L-382 \\ \text { T. K. Fowler } & L-382 \\ \text { C. W. Hartman } & L-387 \\ \text { C. Haussmann } & L-212 \\ \text { R. E. Hester } & L-382 \\ \text { J. } & \text { Killeen } & L-388 \\ \text { H. W. Kruger } & L-96 \\ \text { W. A. Lamb } & L-306 \\ \text { E. J. Lauer } & L-382 \\ \text { J. M. Leary } & L-388 \\ \text { E. P. Lee } & L-388 \\ \text { M. } & L-1 \\ \text { V. K. May . Nei } & L-382 \\ \text { H. W. Patterson } & L-518 \\ \text { L. D. Pearlstein } & L-388 \\ \text { L. } & \text { Smith (LBL) } & \\ \text { M. } & \text { Smith } & L-728 \\ \text { R. } & \text { Spoerlein } & L-711 \\ \text { L. L. Reginato } & L-728\end{array}$

TID

\section{External}

D. W. Padgett, L. Cooper Office of Naval Research 800 North Quincy Street Arlington, Virginia 22217

R. M. Dowe, Jr.

L. A. Kul1

M. P. Fricke

Science Applications Inc.

P. 0. Box 2351

1250 Prospect Street

La Jolla, CA 92037

M. Halling

Navy Underseas Center

San Diego, CA 92132

J. E. Leiss

National Bureau of Standards

301 Connecticut \& Van Ness

Washington, D. C. 20234

C. F. Sharn

Naval Ordnance Systems Command

ORD-032A

Dept. of the Navy

Washingtion, D. C. 20360

L. Levine, M. Friedman

J. Siambis

Naval Research Laboratory

Washington, D. C.

S. V. Yadavalli

Slanford Institute

333 Ravenswood Avenue

Menlo Park, California 94025

NOTICE

"This report was prepared as an account of work sponsored by the United States Government. Neither the United States nor the United States Atomic Energy Commission, nor any of their employes, nor any of their contructors, subcontractors, or thitir employees, makes any warranty, express or implied, or assumes any legal liability or responsibility for the accuracy, completeness or usefulness of any information, apparatus, product or process disclosed, or represents that its use would not infringe privatclyowned rlghts." 